\title{
Editorial
}

\section{Benign Pharyngoesophageal Strictures: Increasingly Encountered and Still a Challenge}

\author{
Dalila Costa ${ }^{a-c}$ Carla Rolanda ${ }^{a-c}$ \\ ${ }^{a}$ Gastroenterology Department, Braga Hospital, Braga, Portugal; ${ }^{b}$ Life and Health Sciences Research Institute \\ (ICVS), School of Medicine, University of Minho, Braga, Portugal; ' ${ }^{\prime} I C V S / 3 B$ 'S, PT Government Associate Laboratory, \\ Guimarães/Braga, Portugal
}

Keywords

Benign strictures - Pharyngoesophageal strictures ·

Radiotherapy · Anastomosis - Dilation - Refractory stricture · Recurrent stricture

\section{Estenoses benignas faringo-esofágicas: um achado crescente ainda desafiante}

\section{Palavras Chave}

Estenoses benignas · Estenoses faringo-esofágicas · Radioterapia · Anastomose · Dilatação · Refractária · Recorrente

Benign pharyngoesophageal stricture (PES) is one of the most frequent post-treatment morbidities in head and neck cancer patients [1]. In fact, the successive interventions and longer patients' survival increased the risk of related complications. PES is mostly associated with radiation therapy in a dose-dependent manner and enhanced by combined chemotherapy or surgery $[1,2]$.

\section{KARGER}

E-Mail karger@karger.com www.karger.com/pjg (c) 2018 Sociedade Portuguesa de Gastrenterologia Published by S. Karger AG, Basel

Korger

Open access

This article is licensed under the Creative Commons AttributionNonCommercial-NoDerivatives 4.0 International License (CC BYNC-ND) (http://www.karger.com/Services/OpenAccessLicense). Usage and distribution for commercial purposes as well as any distribution of modified material requires written permission.
Endoscopic dilation with bougies or balloons is the standard treatment in such strictures, with a considerably effective technical success rate and an acceptable safety profile. Nevertheless, improvement is often transient, requiring recurrent interventions [3]. The goals of therapy are the relief of dysphagia, with the avoidance of complications and the prevention of recurrence. Still, there is no universal definition of therapeutic efficacy. Objective assessment of functional outcomes is less consistent due to significant heterogeneity in the literature [4]; therefore, technical success is most frequently addressed. Kochman et al. [3] previously defined recurrent and refractory esophageal stricture, which are also commonly used as outcome measures.

In this issue of GE - Portuguese Journal of Gastroenterology, Martins et al. [5] report a 3-year experience of treating pharyngoesophageal strictures at a tertiary oncologic center. The overall long-term efficacy of endoscopic dilation program on radiotherapy and anastomotic PES was evaluated. Forty-eight patients included in this study underwent a total of 296 dilations. The preferential dilation technique consisted in Savary bougies dilation done via traditional anterograde access, with a median of 4 dila- 
tions per patient performed with a median interval of 5 weeks. The authors concluded that their endoscopic dilation program was safe and efficient, especially when patient perception of improvement was assessed. Remarkably, this study presents a median follow-up of 29 months. As of now, limited data on long-term follow-up of these specific strictures is available. However, as pointed out by the authors, the small cohort and the retrospective design are important limitations and should be considered when evaluating the results.

Martins et al. [5] defined overall efficacy as dysphagia improvement based on patient perception and a 6-month period of being dilation free and feeding per os. Based on their long-term follow-up results, overall efficacy was reached in 21 patients (58.8\%). A recent meta-analysis [4] reported an estimated overall clinical success rate per patient of $72.9 \%$, though data compared was significantly diverse. Moreover, 15 and 29\% of patients presented with refractory and recurrent PES, respectively, which is in accordance with the literature $[3,6]$, and a gastrostomy tube independence was achieved in $81 \%$ of patients. Notably, patient perception of dysphagia improved in $96 \%$. It seems that small improvements for the patients, even far from the technical endpoints, are worth the laborious repetitions.

Despite the relatively small cohort, Martins et al. [5] revealed on univariate analysis that narrow lumens, recurrent strictures, and a higher number of dilations (some concept redundancy with recurrence) may predict worse outcomes. It supports previous data that also exposed an increasing number of dilations during the first year as a predictive factor for non-responsive PES [7] and severely narrowed strictures as a challenging situation $[2,8]$. Although other characteristics with recognized association to difficult treatment in this setting of aetiology, as stricture length, complexity, and location $[8,9]$, would add value to this analysis if available in a larger population sample. Interestingly, refractory strictures did not present as a worse condition in this population and the authors suggested that these patients may still benefit from endoscopic therapy. The subjective "improvement" of dysphagia included in their definition of efficacy may contribute to this. However, it is known that the long-term outcome of endoscopic treatment for refractory benign esophageal strictures is time-consuming and disappointing with less than one-third of the patients achieving a resolution of the dysphagia, even when other techniques such as steroid injections, incisional therapy, stent placement, or self-bouginage are added to dilation therapy $[5,9]$. Patients and physicians should realize that repeated sessions (with inherent risks) and visits to the hospital will be needed for a possible effective treatment.

Martins et al. [5] also reported a low complication rate $(0.7 \%)$, specifically one deep laceration and one fistula. The infrequent use of more technically challenging dilation techniques (1\%) may have contributed to these results. A recent metanalysis [4] revealed a higher overall complication rate in head and neck cancer patients: $4.4 \%$ for patients undergoing a standard anterograde dilation and $23.3 \%$ for patients undergoing combined anterograde and retrograde dilation technique. Notably, radiation-induced strictures had the highest perforation rate per procedure. Nevertheless, most complications resolved with conservative measures. By the way, the commonly used rule of 3 , also followed by the authors in order to minimize the risk of perforation using bougie dilators, in a recent study did not prove to reduce the risk of adverse events after esophageal dilation [10].

Although benign PES may be challenging, Martins et al. [5] proved that their endoscopic dilation program has a reasonable overall efficacy and a good safety profile. It can be foreseen that in the future, novel therapies and a combination of currently available therapeutic methods should be considered, with promising results in reducing refractory and recurrent strictures $[9,11,12]$. While waiting for further prospective investigation, narrow diameters, recurrent stenosis, and the need for increased numbers of dilations may define a subgroup of patients with unfavorable outcome and alert physicians to the use of alternative approaches.

\section{Disclosure Statement}

The authors have no conflicts of interest to declare.

References

1 McBride SM, Parambi RJ, Jang JW, Goldsmith T, Busse PM, Chan AW: Intensitymodulated versus conventional radiation therapy for oropharyngeal carcinoma: longterm dysphagia and tumor control outcomes. Head Neck 2014;36:492-498.

2 Francis DO, Hall E, Dang JH, Vlacich GR, Netterville JL, Vaezi MF: Outcomes of serial dilation for high-grade radiation-related esophageal strictures in head and neck cancer patients. Laryngoscope 2015;125:856-862.

3 Kochman ML, McClave SA, Boyce HW: The refractory and the recurrent esophageal stricture: a definition. Gastrointest Endosc 2005; 62:474-475. 
4 Moss W, Pang J, Orosco R, Weissbrod P, Brumund $\mathrm{K}$, Weisman R, et al: Esophageal dilation in head and neck cancer patients: a systematic review and meta-analysis. Laryngoscope 2017;128:111-117.

5 Martins D, Pires S, Pimentel-Nunes P, Almeida Silva R, Dias CC, Dinis-Ribeiro M: Endoscopic dilation of pharyngoesophageal strictures: there are more dimensions than a diameter. GE Port J Gastroenterol. DOI: 10.1159/000486608.

6 Repici A, Small A, Mendelson A, Jovani M, Correale L, Hassan C, et al: Natural history and management of refractory benign esophageal strictures. Gastrointest Endosc 2016;84: 222-228.
7 Chapuy CI, Annino DJ, Tishler RB, Haddad RI, Snavely A, Goguen LA: Success of endoscopic pharyngoesophageal dilation after head and neck cancer treatment. Laryngoscope 2013;123:3066-3073.

8 Agarwalla A, Small AJ, Mendelson AH, Scott FI, Kochman ML: Risk of recurrent or refractory strictures and outcome of endoscopic dilation for radiation-induced esophageal strictures. Surg Endosc 2015;29:1903-1912.

9 van Boeckel P, Siersema P: Refractory esophageal strictures: what to do when dilation fails. Curr Treat Options Gastroenterol 2015;13: 47-58.
10 Grooteman KV, Wong Kee Song LM, Vleggaar FP, Siersema PD, Baron TH: Non-adherence to the rule of 3 does not increase the risk of adverse events in esophageal dilation. Gastrointest Endosc 2017;85:332-337.

11 Walter D, Van Den Berg M, Hirdes M, Vleggaar F, Repici A, Ferrara E, et al: A randomized comparison of degradable esophageal stent versus dilation therapy for patients with recurrent benign esophageal strictures: 6-month results (Destiny Study). Gastrointest Endosc 2015;81:AB527.

12 Liu D, Tan Y, Wang Y, Zhang J, Zhou J, Duan $\mathrm{T}$, et al: Endoscopic incision with esophageal stent placement for the treatment of refractory benign esophageal strictures. Gastrointest Endosc 2015;81:1036-1040. 